\title{
ANALISIS STATIK KEKUATAN STRUKTUR FITTING PADA LANDING GEAR PADA PESAWAT N-219
}

\author{
Muhamad Jalu Purnomo \\ Teknik Penerbangan \\ Sekolah Tinggi Teknologi Adisutjipto \\ Jalan Janti Blok R Lanud Adisutjipto, Yogyakarta \\ jalu_p@yahoo.com
}

\begin{abstract}
Aircraft structures to be made stronger in order to be able to withstand the force received. The forces acting on the structure can cause deformation and result in structural failure. All components of the structure of the aircraft is an important part and it requires a good working resilience to maintain the security (safety). One important component of the aircraft that must be considered is the structure of the landing gear fittings. Fitting is contained in the structure that functions held their landing gear load received all the landing gear and as an intermediary for the landing gear and airframe structure of the aircraft. Because Landing Gear is one important component in the structure of the aircraft. Strength landing gear fittings will be calculated at the time of landing, the burden derived from the speed of the aircraft landing and aircraft load.
\end{abstract}

Keywords: landing gear, fitting

Abstrak

Struktur pesawat harus dibuat kuat agar mampu menahan gaya yang diterima. Gaya yang bekerja pada struktur dapat menyebabkan terjadinya perubahan bentuk dan berujung pada kegagalan struktur. Semua komponen struktur pada pesawat terbang merupakan bagian penting dan sangat membutuhkan ketahanan kerja yang baik untuk menjaga keamanan (safety). Salah satu komponen penting dari pesawat terbang yang harus diperhatikan adalah struktur fitting pada landing gear. Fitting merupakan salah struktur yang terdapat pada landing gear yg berfungsi manahan semua beban yang diterima landing gear dan sebagai perantara untuk landing gear dan struktur airframe pesawat. Karena landing gear merupakan salah satu komponen penting dalam struktur pesawat terbang. Kekuatan fitting landing gear akan dihitung pada saat landing, yang bebannya diperoleh dari kecepatan pesawat mendarat dan beban pesawat.

Kata kunci: landing gear, fitting.

\section{Latar Belakang}

Struktur pesawat harus dibuat kuat agar mampu menahan gaya yang diterima meski sebenarnya masih dapat diterima selama masih dalam batas pakai yang dapat ditoleransi. Sedangkan perubahan bentuk (deformation) dapat didefinisikan sebagai perubahan bentuk yang masih dalam daerah elastisitasnya namun akan menyebabkan deformasi permanen yang disebabkan oleh perlakuan gaya yang berulang pada struktur tersebut sehingga menyebabkan deformasi permanen dan gagal struktur. Landing Gear merupakan salah satu komponen penting dalam struktur pesawat terbang, karena berfungsi untuk menopang keseluruhan bobot 
pesawat ketika berada didarat, mobilisasi di daratan (ground operation), kondisi tinggal landas (take-off conditions) dan pada saat pendaratan pesawat (landing). Dalam penelitian ini akan menghitung kekuatan struktur pada fitting pada pesawat N-219 ketika menahan beban pesawat saat melakukan pendaratan.

\section{Landing Gear}

Landing Gear merupakan salah satu komponen penting dalam struktur pesawat udara. Berikut ini fungsi landing gear:

a. Menahan beban pesawat udara saat pesawat berada didarat

b. Menahan beban saat pesawat melakukan touch down.

c. Menyerap energi kinetik yang terjadi sehubungan dengan kecepatan jatuh.

d. Merubah gerakan terbang menjadi gerakan gelinding

e. Menghentikan pesawat saat mendarat

Pada pesawat N-219 jenis landing gear menganut konsep rectractable tricycle landing gear. Struktur main landing gear N-219 ditunjukkan pada Gambar 1.

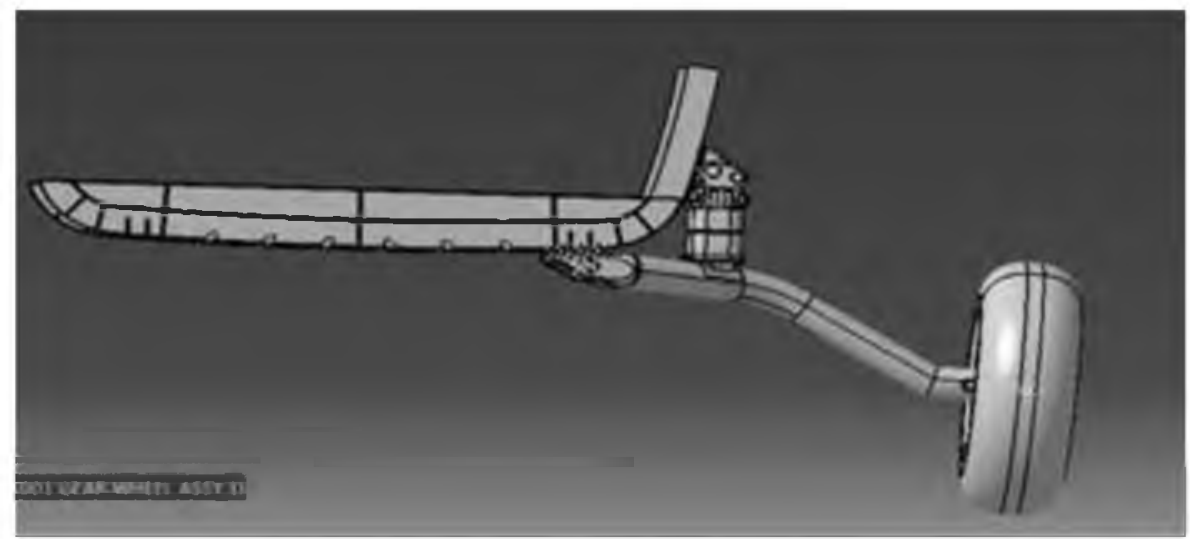

Gambar 1. Struktur Main Landing Gear N-219

Beban landing adalah beban-beban yang terjadi selama pesawat melakukan landing, meliputi beban aksial, oblique load dan transverse load yang terjadi saat pesawat mendarat. Besarnya nilai pembebanan pada saat landing dipengaruhi oleh beberapa hal, diantaranya kecepatan landing, sudut landing, kemampuan tire dan shock absorber, maximum landing weight.

\section{Fitting}

Fitting adalah salah satu bagian part struktur landing gear yang menghubungkan dengan airframe. Peranan fitting adalah untuk menahan beban yang diterima landing gear pada saat pesawat melakukan take-off maupun pada saat landing. Pada landing gear pesawat N-219 memilki 8 bilah fitting pada main landing gear (lihat Gambar 2 dan Gambar 3), masing-masing terdapat 4 fitting yaitu 2 di bagian atas dan 2 di bagian bawah. Dalam penelitian ini penulis menghitung kekuatan struktur fitting pada 2 bilah fitting yang letaknya di bagian bawah 


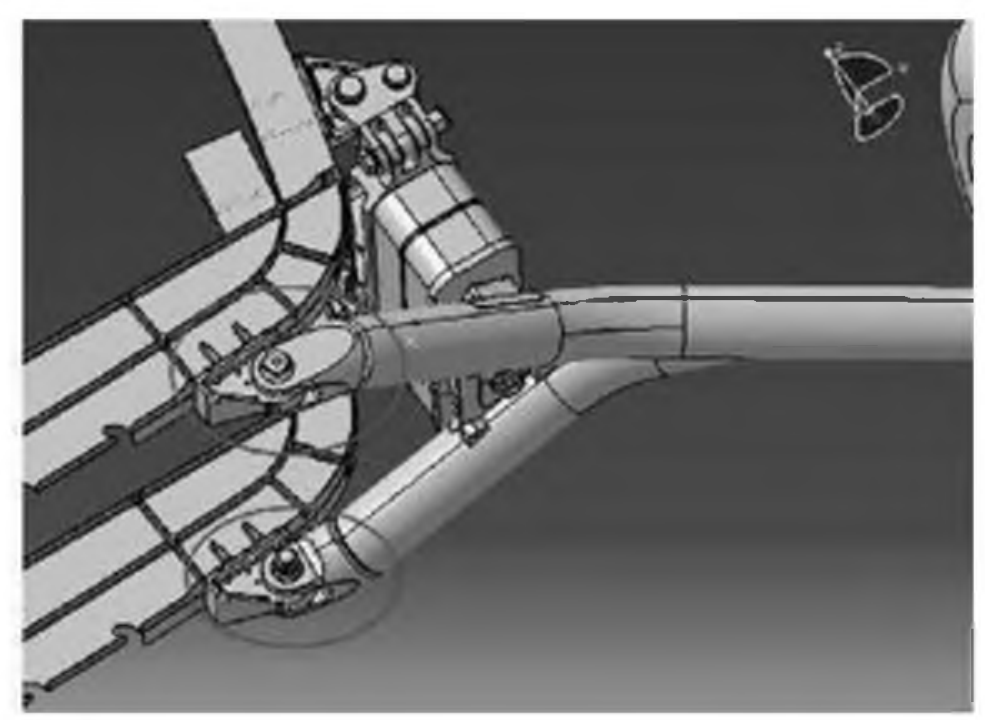

Gambar 2. Struktur fitting pada main landing gear
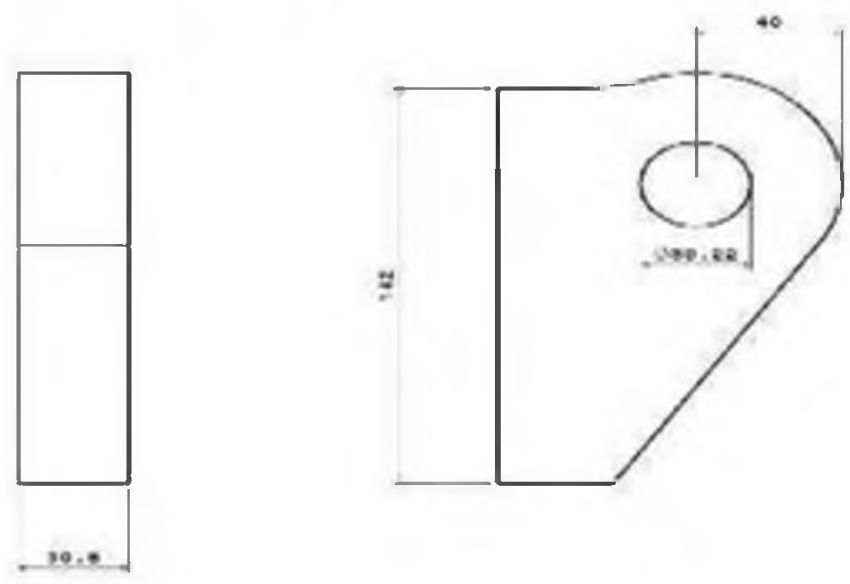

Gambar 3. Fitting

(sumber: Michael_Niu Structural Design)

Diketahui :

MTOW $=16.000 \mathrm{lb}=7257,44 \mathrm{~kg}=7257,44 \mathrm{dN}$

Factor of safety $=1,5$

$\mathrm{G}$ Force $=2,67$

$\mathrm{RW}_{\mathrm{w}}=7257,44 \times 1,5 \times 2,67=29066,0472 \mathrm{~kg}=29066,0472 \mathrm{dN}$

$\mathrm{a}=962 \mathrm{~mm}$

$\mathrm{b}=383 \mathrm{~mm}$

$\Sigma \mathrm{MRf}=0$

$$
\begin{gathered}
R w \cdot(a+b)-R f u \cdot(a)=0 \\
R f u=\frac{R w \cdot(a+b)}{b} \\
R f u=\frac{29066,0472 \times 1345}{383}=102072,6723 \mathrm{dN} / \mathrm{mm}^{2} \\
R f u s=R f u-R w \\
R f=102072,6723-29066,0472=73006,62508 \mathrm{dN} / \mathrm{mm}^{2}
\end{gathered}
$$


Karena fitting pada main landing gear dibagian bawah terdapat 2 bilah maka beban yang diterima fitting dibagi dengan 2, maka $R f u s=73006,62508 / 2=36503,3 \mathrm{dN} / \mathrm{mm}^{2}$. Jadi, beban yg diterima pada setiap fitting adalah $36503,3 \mathrm{dN} / \mathrm{mm}^{2}$

\section{Perhitungan pada Touch down} berikut.

Adanya beban pada saat landing gear menyentuh landasan, deskripsinya sebagai

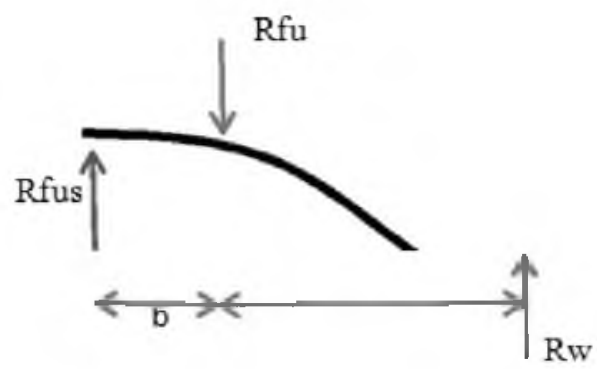

Diketahui :

Gambar 4. Free body diagram landing gear

$$
\begin{aligned}
& \text { MTOW }=16.000 \mathrm{lb}=7257,44 \mathrm{~kg}=7257,44 \mathrm{dN} \\
& \text { Factor of safety }=1,5 \\
& \mathrm{G} \text { Force }=2,67 \\
& \text { Berat total }=7257,44 \times 1,5 \times 2,67=29066,0472 \mathrm{dN} \\
& \text { Berat masing-masing main landing gear }=29066,0472 \mathrm{~kg} / 2=14533,09953 \mathrm{dN} \\
& \begin{array}{l}
\text { MRf }=0 \\
\qquad R w \cdot(a+b)-R f u \cdot(a)=0 \\
\qquad R f u=\frac{R w \cdot(a+b)}{b} \\
R f u=\frac{14533,09953 \times 1345}{383}=5 \cdot 1036,6028 \mathrm{dN} / \mathrm{mm}^{2} \\
R f u s=R f u-R w \\
R f=51036,6028-14533,09953=36503,5 \mathrm{dN} / \mathrm{mm}^{2}
\end{array}
\end{aligned}
$$

Karena fitting pada main landing gear dibagian bawah terdapat 2 bilah maka beban yang diterima fitting dibagi dengan 2, maka Rfus $=36503,5 / 2=18251,75 \mathrm{dN} / \mathrm{mm}^{2}$. Jadi, beban yg diterima pada setiap fitting adalah $18251,75 \mathrm{dN} / \mathrm{mm}^{2}$.

\section{Perhitungan pada lug fitting}

Diketahui:

$$
\begin{array}{ll}
- \text { Material } & =\text { alloysteel } 4340 \text { per AMS } 6414 \\
\text { - Ftu } & =260 \mathrm{ksi}=182 \mathrm{~kg} / \mathrm{mm}^{2} \\
\text { - Fty } & =217 \mathrm{ksi}=152 \mathrm{~kg} / \mathrm{mm}^{2} \\
\text { - } \mathrm{W} & =142 \mathrm{~mm} \\
-\mathrm{t}=\mathrm{t} 2 & =30,5 \mathrm{~mm} \\
-\mathrm{t} 1 & =17,5 \mathrm{~mm}
\end{array}
$$


$\begin{array}{ll}-\mathrm{a} & =40 \mathrm{~mm} \\ \text { - } \mathrm{D} & =30,22 \mathrm{~mm}\end{array}$

- $P$ (beban pada fitting) $=18251,75 \mathrm{dN} / \mathrm{mm}^{2}$

a. Axial Load

Shear bearing load

$$
P_{b r u}=K_{b r} \cdot A_{b r} \cdot F_{t w x}
$$

- $\frac{a}{D}=\frac{40}{30,22}=1,32 ; \frac{D}{t}=\frac{30,22}{30,5}=0,99 ;$ dari tabel $K_{b r}=1,28$

- $A_{b r}=$ D.t

$$
=30,22 \times 30,5=921,71
$$

- $P_{\text {bru }}=1,28 \times 921,71 \times 182=214721,5616 \mathrm{dN} / \mathrm{mm}^{2}$

- $M S=\frac{P_{b r u}}{1,15 p}-1$

$$
=\frac{214721,5616}{1,15(18251,75)}-1=9,22994515
$$

Tension failure load

$$
P_{\mathrm{bs}}=K_{r} \cdot A_{s} \cdot F_{\mathrm{s}}
$$

- $\frac{w}{D}=\frac{140}{30,22}=4,633$; dari tabel $\mathrm{Kt}=2,45$

- $A_{t}=\left(w-D_{b}\right) t$

$$
=(140-25,4) \cdot 30,5=3495,3
$$

- $P$ tu $=2,45 \times 3409,29 \times 182=1520202,411 \mathrm{dN} / \mathrm{mm}^{2}$

- $M S=\frac{P_{\text {tus }}}{1,15 P}-1$

$$
=\frac{1558554,27}{1,15(18251,75)}-1=71,42676127
$$

\section{Allowable yield load}

$$
P_{y}=C\left(\frac{F_{4}}{F_{a x}}\right)\left(P_{x}\right)_{\text {min }}
$$

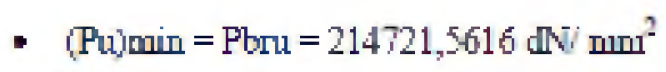

- Abr. Fur $=15775122$

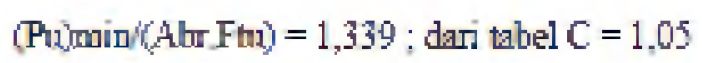




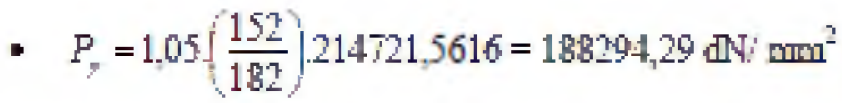

$$
\begin{aligned}
\text { - MS } & =\left(\frac{P_{y}}{\left(\frac{P}{1,5}\right)}\right)-1 \\
& =\frac{189294,29}{\left(\frac{18251,75}{1,5}\right)}-1=14,4,7475994
\end{aligned}
$$

b. Transverse load

\section{Ultimate bearing load}

$$
\begin{aligned}
& F_{\mathrm{w} r \mathrm{u}}=K_{\mathrm{a}} A_{\mathrm{pr}} F_{\mathrm{a}} \\
& \text { - } A_{b r}=D t=30,22 \times 305=921,71 \\
& \text { - } A_{a r}=\frac{6}{\left(\frac{3}{A_{1}}\right)+\left(\frac{1}{A_{2}}\right)+\left(\frac{1}{A_{1}}\right)+\left(\frac{1}{A_{4}}\right)} \\
& A_{1}=A_{4}=\left(a-\frac{D_{b}}{2} \sin 4 y^{0}\right)+\left(40-\frac{30,22}{2} \sin 45\right) \times 30,5 \\
& =894,175515 \\
& A_{2}=A_{1}=\left(a-\frac{D_{b}}{2}\right) t=\left(40-\frac{30,27}{2}\right) \times 30,5=759.14 \overline{\mathrm{i}} \\
& A_{m}=\frac{6}{\left(\frac{3}{994,175515}\right)+\left(\frac{1}{759,145}\right)+\left(\frac{1}{759,145}\right)+\left(\frac{1}{994,175515}\right)} \\
& =\frac{6}{(0,003355046)+(0,001317271)+(0,001317271)+(0,001118349)} \\
& =\frac{6}{0007107937}=8411257249 \\
& \text { - } \frac{A_{s v}}{A_{o x}}=\frac{84,1257249}{92171}=0,915 \longrightarrow \text { dapat darj tatbel Ktu }=1,04
\end{aligned}
$$

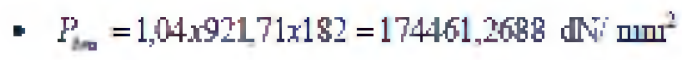

$$
\begin{aligned}
& \text { - } M S=\left(\frac{P_{\text {bu }}}{115 \mathrm{~F} P}\right)-1 \\
& M S=\left(\frac{174461,2688}{(115 \times 18251,75)}\right)-1=7,3
\end{aligned}
$$


Yield Load

- $P_{y}=K_{p} A_{b o} F_{y}$

- $\frac{A_{\text {orr }}}{A_{\text {sr }}}=\frac{844,1257249}{921,71}=0,915 \longrightarrow$ dapat dari tabel Kty $=0,97$

- $P_{y}=0,97 x 921,71 \times 152=135896,9224 \mathrm{dN} / \mathrm{mm}^{2}$

- $M S=\left(\frac{P_{y}}{\left(\frac{P}{1,5}\right)}\right)-1$

- $M S=\left(\frac{135896,9224}{\left(\frac{18251,75}{1,5}\right)}\right)-1=10,16$

c. Oblique Load

\section{Ultimate Load}

- $\quad$ Pbru Axial $=214721,5616 \mathrm{dN} / \mathrm{mm}^{2}$

- Ptu Axial $=1558554,27 \mathrm{dN} / \mathrm{mm}^{2}$

- Pbru Transverse $=174461,2688 \mathrm{dN} / \mathrm{mm}^{2}$

- $M S=\frac{1}{1,15\left(R_{a}^{16}+R_{\sigma}^{1,6}\right)^{0,255}}-1$

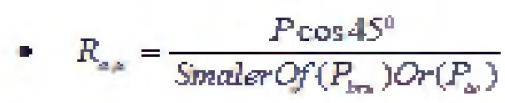

$$
=\frac{36503,3 \times C a r 45^{\circ}}{214721,5.516}=\frac{25807,8331}{214721,5616}=0,12
$$

- $\bar{r}_{\mathrm{r}, u}=\frac{P \sin 45^{0}}{P_{\mathrm{n}}}=\frac{36503,3 \sin 45^{\circ}}{174461,2698}=0,146$

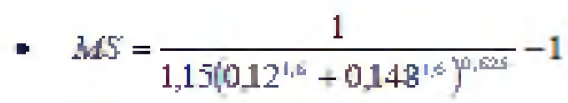

$$
\begin{aligned}
& =\frac{1}{115(0,033627145+0,04703474)^{0,635}}-1 \\
& =\left(\frac{1}{0,238432563}\right)-1=3,194
\end{aligned}
$$




\section{Yield Load}

- Py axial $=188294,29 \mathrm{dN} / \mathrm{mm}^{2}$

- Py Transverse $=135896,9224 \mathrm{dN} / \mathrm{mm}^{2}$

- $M S=\frac{1}{1,15\left(R_{a, y}{ }^{1.6}+R_{v, y}{ }^{1,6}\right)^{0.625}}-1$

- $R_{e, y}=\frac{\left(\frac{P}{1,5}\right) \operatorname{Cos} 45^{\circ}}{P y}=\frac{\left(\frac{36503,3}{1,5}\right) \times 0,707}{188294,29}=0,091374104$

- $R_{p, y}=\frac{\left(\frac{P}{1,5}\right) \operatorname{Sin} 45^{\circ}}{P y}=\frac{\left(\frac{36503,3}{1, \overline{1}}\right) \times 0,707}{135895,9224}=0,1266044943$

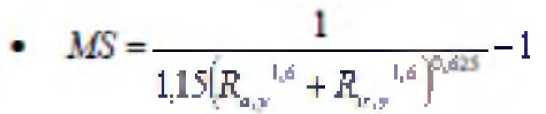

$$
\begin{aligned}
& =\frac{1}{1.15\left(0,0913741044^{16}+0,126604943^{14}\right)^{40,25}}-1 \\
& =\frac{1}{1.15(0,0217428777+0,036537097)^{1,625}}-1 \\
& =\frac{1}{1,15[0,169401)}-1=\left(\frac{1}{0,194911}\right)-1=4,133
\end{aligned}
$$

\section{Kesimpulan}

Dalam analisis kasus tegangan pada struktur fitting pada pesawat $\mathrm{CN}-219$ yang terletak diantara di landing gear disimpulkan sebagai berikut :

1. Hasil perhitungan nilai tegangan pada lug fitting yakni, shaer bearing load, tension load dan yield load, dan perhitungan pada lug fitting.

Touch down mengunakan Two main landing gear

\begin{tabular}{|l|l|l|l|l|}
\hline No & \multicolumn{2}{|c|}{ Keterangan } & Nilai Tegangan & Nilai M.S \\
\hline \multirow{4}{*}{1.} & Lug Fitting & Shear bearing load & $214721,5616 \mathrm{dN} / \mathrm{mm}^{2}$ & 9,22 \\
\cline { 2 - 5 } & Axial Load & Tension failure load & $1520202,411 \mathrm{dN} / \mathrm{mm}^{2}$ & 71,4267 \\
\cline { 2 - 5 } & & Allowable yield load & $188294,29 \mathrm{dN} / \mathrm{mm}^{2}$ & 14,47 \\
\cline { 2 - 5 } & & Shear bearing load & $174461,2688 \mathrm{dN} / \mathrm{mm}^{2}$ & 7,3 \\
\cline { 2 - 5 } & Transverse Load & Allowable yield load & $135896,9224 \mathrm{dN} / \mathrm{mm}^{2}$ & 10,16 \\
\cline { 2 - 5 } & Oblique Load & Ultimate load & - & 3,194 \\
\cline { 2 - 5 } & Allowable yield load & - & 4,133 \\
\hline
\end{tabular}




\section{Daftar Pustaka}

E.F.Bruhn,B.S, M.S., C.E., Dr. Eng., 2009, Analysis And Design Of Flight VehiclesStructures. Jacob Publishing, Inc. 101 East Carmel Drive Suite.

Wijaya, Ayu. Analisa Kekuatan Mian Landing Gear Back up Structure pada Pesawat mengunakan MSC Patran/Nastran. Perpustakan Sekolah Tinggi Teknologi Adisutjipto. Yogyakarta. 2014.

Military Handbook, 2003, Metalic Materials And Element For Aerospace VehicleStructures. US Government Printing Office.

Niu, Michael C.Y., 2001, Airframe Stress Analysis And Sizing. Conmilit Press Ltd. Hongkong.

Niu, Michael C.Y. Airframe Structural Design. Lockheed Aeronautical System 
Muhamad Jalu Purnomo 